\title{
SUS: da perda da radicalidade democrática ao novo desenvolvimentismo
}

\author{
Tânia Regina Krüger
}

Universidade Federal de Santa Catarina (UFSC)

\section{SUS: da perda da radicalidade democrática ao novo desenvolvimentismo}

Resumo: Este texto apresenta uma contextualização da política de saúde no Brasil, tratando propriamente da implementação do Sistema Único de Saúde (SUS), nos anos de 1990 e 2000. Tem por objetivo fazer algumas reflexões sobre a direção que a política de saúde foi tomando a partir da implementação do SUS, tendo como referências as bandeiras que o Movimento da Reforma Sanitária conseguiu institucionalizar na Constituição de 1988 e nas leis orgânicas da saúde. A premissa que norteia as reflexões deste texto é que nos anos de 1990 houve uma perda da radicalidade democrática com a política neoliberal e nos anos 2000 esta perda da radicalidade democrática tem continuidade e se soma a perspectiva do novo desenvolvimento.

Palavras-chave: SUS. Política de saúde. Desenvolvimento.

\section{SUS: from the Loss of Radical Democracy to New Developmentalism}

Abstract: This study places Brazilian healthcare policy in context, specifically the implementation of the Single Healthcare System (SUS) in the 1990s and 2000. Its purpose is to reflect on the direction that healthcare policy took, based on the implementation of SUS, using as references the work goals that the Healthcare Reform Movement was able to institutionalize in the Constitution of 1988 and in the organic healthcare laws. The premise that guided the reflections of this paper is that in the 1990s there was a loss of democratic radicality and a rise in neoliberal policies and in the first decade of the new century this loss of democratic radicality continued and combined with a new developmentist perspective.

Keywords: SUS. Healthcare policy. Development. 


\section{Introdução}

Este texto apresenta uma contextualização da política de saúde, tratando propriamente da implementação do SUS, nos anos de 1990 e 2000, com enfoque na atuação política dos governos Collor, Fernando Henrique, Lula e Dilma Roussef. O trabalho tem por objetivo fazer algumas reflexões sobre a direção que a política de saúde tem tomado, tendo como referências as reivindicações para a saúde pública brasileira que o Movimento da Reforma Sanitária conseguiu institucionalizar na Constituição de 1988 e nas leis orgânicas da saúde. Estas reivindicações foram bandeiras de lutas que estão institucionalizadas no conceito ampliado de saúde, nas diretrizes, nos objetivos, nos princípios e nas competências do SUS e, sobretudo, na grande frase: a saúde como direito de todos e dever do Estado. Estas bandeiras são, em nosso entender, os fundamentos do SUS, pois além de conterem diretrizes e princípios organizacionais possuem também princípios doutrinários. É neste conjunto de fundamentos que identificamos um projeto de saúde pública que ultrapassa a dimensão do serviço e contempla uma proposta de Estado democrático e de direito, indicando um projeto de radicalidade democrática para a sociedade brasileira com enfoque na saúde.

O texto se compõe de itens que caracterizam a política de saúde nos anos de 1990, quando o país mergulha na conjuntura neoliberal e as bandeiras do SUS perdem sua vitalidade democrático-popular. A seguir, caracterizamos também a política de saúde a partir dos anos de 2000, no momento em que a lógica neoliberal é questionada e nasce a perspectiva de saúde e desenvolvimento que dará a base para o terceiro item. Buscamos rapidamente situar os fundamentos do novo desenvolvimentismo e fazer a identificação das principais linhas de pensamento sobre o tema. Por fim, concluímos com algumas indicações e reflexões sobre como a política do novo desenvolvimentismo está impactando no SUS e o fazendo perder sua radicalidade democrática.

\section{O SUS nos anos 1990: a perda da radicalidade democrática}

O Brasil chegou aos anos de 1990 com um arcabouço legal que indicou algumas bases da cidadania e da democracia moderna, com possibilidades na redução das taxas de exploração do trabalho e uma conquista social que só foi possível graças à mobilização dos setores populares no momento em que as forças ditatoriais agonizavam. No momento da implementação dos direitos sociais reconhecidos, entre eles, o da saúde, impõese uma nova conjuntura econômico-política, que influenciará significativamente a sua dinâmica. Assim a implementação do SUS se deu com a intensificação das práticas políticas e econômicas neoliberais e da perda substantiva do conteúdo progressista da democracia. Em relação à saúde, o conteúdo da Constituição de 1988, expressa uma perspectiva inovadora em relação aos direitos sociais e significa uma inserção política de sujeitos sociais, até o momento, excluídos na conformação da agenda pública. O direito universal à saúde reafirma o trânsito para um Estado Institucional-redistributivo, na medida em que apresenta indicações de rompimento com a sujeição histórica dos direitos sociais ao trabalho formal e sinaliza para a atenção às necessidades integrais de saúde do cidadão. Os serviços e as determinações da saúde indicados no texto constitucional articulam os setores social e econômico, não tratando, desse modo, a distribuição de bens e serviços sociais autonomizados da esfera da produção.

Mas a conquista formal dos direitos sociais historicamente não tem sido garantia de realização. Posteriormente à restauração do padrão de governabilidade democrática, via Constituição e eleição presidencial, as elites econômicas, políticas e intelectuais conservadoras, que viam a década de 1980 como a década perdida pela estagnação econômica e não um período marcado pela interlocução das forças democrático-populares, abriram espaço para o pensamento econômico e político neoliberal que já estava se consolidando nos países centrais.

Os governos Collor de Mello e Fernando Henrique Cardoso por toda a década de 1990, com diferentes modalidades, questionaram as aspirações democráticas da década de 1980 e da Constituição de 1988 e as colocaram como empecilho à governabilidade. Apesar do zelo ideológico do neoliberalismo em realizar este movimento em nome de uma suposta abertura comercial e concorrência internacional, modernização e desregulamentação, o que se evidenciou foi um amplo dogmatismo econômico. Em relação à administração pública, os membros dos governos e também da esquerda foram dogmáticos em suas ações e propostas de manejo do déficit fiscal.

As orientações contidas no Plano Diretor da Reforma do Estado de 1995 não deixaram dúvidas quanto ao novo perfil estatal que o governo brasileiro pretendia e para isto construiu todo um consenso favorável, tendo como parceiras as elites políticas e econômicas. O Plano da Reforma do Estado propunha quatro pressupostos: redução de tamanho e de funções, pela via da privatização, terceirização e publicização; redução do grau de interferência estatal, repassando a função reguladora em favor de mecanismos de controle via mercado; aumento da governança e retorno da governabilidade, com o aperfeiçoamento da democracia representa- 
tiva (PEREIRA, 1997). Esta Reforma se sustentou no clima de satanização do Estado (BORÓN, 1995), criado nos anos anteriores e o que era para ser uma questão administrativa acabou se tornando uma questão que dizia respeito aos princípios da democracia e da participação popular. Na avaliação de Fiori (2013, p. 31), este foi um "longo período de alinhamento quase automático do país às grandes potências ocidentais" e para Sader (2013), esta conjuntura tirou de cena a polarização entre democracia e ditadura, e o processo de democratização se esgotou sem ter democratizado o poder econômico no Brasil.

O processo de implementação do SUS no início dos

\section{Os serviços e as determinações}

da saúde indicados no texto

constitucional articulam os

setores social e econômico, não

tratando, desse modo, a

distribuição de bens e serviços

sociais autonomizados da

esfera da produção. anos de 1990 encontrou vários desafios. Os vetos aos artigos que diziam respeito ao financiamento e à participação da comunidade no texto da Lei 8.080 ilustram bem os parâmetros do governo Collor. A partir da regulamentação do SUS (Lei 8.080 e 8.142/1990) a conjuntura instalada propiciou o refluxo nas principais entidades que constituíram o Movimento Sanitário nas décadas anteriores. Esse refluxo tem relação direta com as novas determinações da conjuntura internacional e nacional, a ênfase ideológica do neoliberalismo e as ações sofridas pelos representantes do Estado que não pouparam esforços para desqualificar e neutralizar qualquer movimento contestatório. A implementação do SUS nesta década foi objeto de desfinanciamento, sucateamento e recentralização. Esta dinâmica de recentralização, comandada por José Serra, então Ministro da Saúde, apesar de manter no espaço público um discurso de valorização da participação, ignorou a instância dos gestores, que é a Comissão Intergestora Tripartite (CIT) e o Conselho Nacional de Saúde.

Destacamos outros elementos que caracterizam, em nosso entender, as bases para a perda da radicalidade democrática do SUS e provocaram inúmeros constrangimentos:

- adiamento da $9^{\text {a }}$ Conferência Nacional de Saúde de 1990 para 1992, que aconteceu poucos dias antes do impeachment;

- atraso na municipalização que só foi deslanchada após o documento A ousadia de cumprir e fazer cumprir a lei, que resultou da $9^{\text {a }}$ Conferência Nacional de Saúde;

- na Lei de Diretrizes Orçamentárias de 1994, o ministro da Previdência Antônio Britto suspendeu o repasse dos 30\% dos recursos do Orçamento da Seguridade Social que eram destinados à saúde desde 1989, por entender que estes recursos deveriam sair do orçamento fiscal, num claro desrespeito ao art. 195 da Constituição e art. 55, do Ato das Disposições Constitucionais Transitórias;

- três meses após a posse, o governo FHC encaminhou ao Congresso a Proposta de Emenda Constitucional (PEC 21 de 28/03/1995) com vistas a conseguir governabilidade no âmbito da Seguridade Social. No que diz respeito à saúde, a proposta era alterar o artigo 196 da Constituição: Saúde é direito de todos e dever do Estado. Sua proposta acrescentava, ao final dessa frase: nos termos da lei. A ameaça a este preceito se dava em apenas três palavras, pois remetia a realização deste dispositivo à lei infraconstitucional e poderia acabar com a universalidade. A tramitação desta PEC foi extremante polêmica e o próprio governo retirou de pauta em $29 / 11 / 1995^{1}$.

- a Lei $\mathrm{n}^{\circ}$ 9.656/1998, resultado de um conflituoso debate parlamentar, criou normas e procedimentos a serem observados pelas pessoas jurídicas de direito privado que operam planos ou seguros privados de assistência à saúde. Cabendo destacar, come alguma inovação, que o setor privado deveria ser fiscalizado pela Agência Nacional de Saúde Suplementar (ANS) e restituir ao SUS quando prestasse atendimentos aos seus clientes. As negociações destas conquistas levaram à alteração sorrateira do inciso terceiro do artigo 199 da Constituição em seu inciso $\S 3^{\circ}$ : "É vedada a participação direta ou indireta de empresas ou capitais estrangeiros na assistência à saúde no País, salvo nos casos previstos em lei". Passando a ter o seguinte texto: "As pessoas físicas ou jurídicas residentes ou domiciliadas no exterior podem constituir ou participar do capital, ou do aumento do capital, de pessoas jurídicas de direito privado constituídas sob as leis brasileiras para operar planos privados de assistência à saúde” (Redação dada pela Medida Provisória n. 2.177-44, de 2001). (BRASIL, 2001).

- o Plano da Reforma do Estado, ao criar os serviços não exclusivos do Estado, tinha como objetivo transferir para o setor público não estatal os Serviços Sociais Competitivos (PEREIRA, 1997). A regulamentação desta forma de gestão se deu pela Lei n. ${ }^{\circ}$ 9.637/1998, que tem como objetivo qualiûcar como organizações sociais, pessoas jurídicas de direito privado sem ûns lucrativos, cujas atividades sejam dirigidas ao ensino, à pesquisa, à tecnologia, à proteção e preservação do meio ambiente, à cultura e à saúde. Em seguida, aparecem 
as Organizações da Sociedade Civil de Interesse Público (Oscip), (Lei 9.790/1999 e decreto 3.100/1999), instituída com a possibilidade de celebração de parceria com o Poder Público.

Além destes elementos ainda podemos citar o início da implementação do Programa de Saúde da Família como uma cesta básica da saúde para os pobres, com financiamento do Banco Mundial (BRAVO, 2007); as inúmeras normatizações que foram fatiando a perspectiva de uma gestão e o trato integral das necessidades de saúde, a descentralização sendo realizada como desconcentração de ações e com concentração de decisões e de recursos no nível federal. Outro elemento importante da descentralização enviesada foi a aprovação da Emenda Constitucional 29, em 2000, que definiu os percentuais dos recursos próprios a serem aplicados na saúde pelas esferas municipal (15\%) e estadual (12\%), sem definir o percentual da União.

Estes elementos apontados acima caracterizam as bases para a perda da radicalidade democrática que foi decisiva na construção do SUS e provocou, no processo de implantação, inúmeros constrangimentos.

Por outro lado, o Movimento da Reforma Sanitária durante a década de 1990 ficou em posição defensiva, apenas resistindo aos ataques ao SUS (BRAVO; MENEZES, 2010). Ficou evidente sua fragilidade político-organizacional para enfrentar o desfinanciamento, a desregulamentação, a desconcentração e a recentralização da implementação do SUS. A reafirmação do SUS, como política pública universal, de caráter coletivo e obrigação do Estado, na maioria das vezes, nos espaços dos Conselhos e Conferências, ficou reduzida a reivindicações por serviços de saúde, organização da rede nos municípios e contratação de pessoal.

Uma síntese desta década em relação à saúde brasileira pode ser encontrada em Bravo (2007), que caracteriza a tensão entre os dois projetos: da Reforma Sanitária e o projeto privatista da saúde, que vem se tornando hegemônico desde a metade da década de 1990. Todos os constrangimentos na implementação do SUS vêm fortalecendo o projeto da saúde articulado ao mercado. Segundo Nogueira (2002), o setor da saúde passa por uma transição: de uma atividade centrada no bem-estar e com sentido humanitário, se transformando em uma atividade orientada e mediada por padrões de racionalidade instrumental e o lucro. Assim, transita de um bem social para um bem individual, de um bem de direito social para um bem de direito civil.

\section{O SUS nos anos 2000: da perda da radicalidade democrática à saúde como desenvolvimento}

Em 2002, a vitória de Lula, do Partido dos Trabalhadores (PT), teve um significado real e simbólico para um país como o Brasil, dotado de enorme conservadorismo e desigualdades. Foi uma vitória tardia, depois de uma década de desertificação social e econômica. Para poder vencer, o PT fez muitas concessões, abandonou várias bandeiras que o caracterizaram desde 1979 e aliou-se a grupos políticos de centro-direita vinculados ao capital industrial. Os maiores desafios do PT se concentrariam em: responder as reivindicações imediatas do mundo do trabalho para enfrentar a degradação salarial e o desemprego; realizar reforma agrária; impulsionar o patamar tecnológico para responder as carências dos trabalhadores; limitar a expansão da especulação do capital-dinheiro; incentivar a produção de bens socialmente úteis e recuperar o sentido público, coletivo e social das atividades estatais. Este tipo de política é típico das democracias burguesas e não significava qualquer pretensão de superação da lógica predominante, pois os elementos desfavoráveis possuíam o risco do continuísmo, dado o peso social, econômico e político que suas forças exercem (ANTUNES, 2004). No entanto, segundo Belluzzo (2013, p. 108), o presidente Lula buscou os riscos do apoio de uma base pluriclassista, perseguiu a imagem de um líder popular, mas sempre disposto à mediação entre a esperança e os princípios "tentando se equilibrar [...] entre as ações que buscavam a elevação dos padrões de vida dos mais pobres e as decisões de política econômica que propiciaram os ganhos parrudos aos senhores das finanças".

Neste governo, Humberto Costa assumiu o Ministério da Saúde levando para os quadros dirigentes pessoas reconhecidas por sua militância política e intelectual na Reforma Sanitária e na defesa do SUS. Houve inicialmente na saúde, como nas demais políticas sociais, uma reanimação das forças progressistas. Especificamente sobre a política de saúde no início do governo Lula, pode-se destacar alguns aspectos positivos, como: o retorno da concepção de Reforma Sanitária em discursos e documentos do Ministério; escolha de profissionais comprometidos com a Reforma Sanitária para ocupar o segundo escalão do Ministério da Saúde; o tímido retorno da concepção de Seguridade Social; a participação do ministro nas reuniões do Conselho Nacional de Saúde (CNS) e a convocação extraordinária da $12^{\mathrm{a}}$ Conferência Nacional de Saúde em 2003 e da $13^{\mathrm{a}}$ em 2007 (BRAVO, 2007); a aprovação da Política de Atenção Básica em 2006; a ênfase na Estratégia de Saúde da Família como serviço estruturante e porta de entrada preferencial do SUS; incentivo à formação de profissionais de saúde com perfil para trabalhar no SUS em parceria com universidades e secretarias de saúde e a aprovação da Política Nacional de Medicamentos.

Ao mesmo tempo evidenciam-se pontos que foram limitantes dos aspectos tratados como progressistas, entre eles: a concepção de Seguridade Social aparece desarticulada da Previdência e Assistência Social; 
continuidade da proposta de Agentes Comunitários de Saúde e a política de educação para o SUS, que pretere as unidades de ensino (sobretudo as universidades públicas) em favor das organizações não governamentais (BRAVO, 2007); a permanência das indefinições quanto a um financiamento estável para a saúde e a não aprovação do Plano de Cargos, Carreira e Salários (PCCS) único para o SUS. A participação do Ministro nas reuniões do CNS aconteceu até o momento em que um representante dos trabalhadores da saúde foi eleito presidente e este colegiado não aprovou o projeto de gestão do serviço público pautado no direito privado Fundação Estatal de Direito Privado.

As características progressistas foram mais evidentes no início do governo. No decorrer da gestão houve um recrudescimento do conservadorismo que se tornou visível através da condução das ações e com a troca dos técnicos dirigentes reconhecidamente vinculadas à defesa do SUS. Desse modo, indica-se que o processo regressivo e conservador, que marcou a era FHC e José Serra na saúde, teve raros instantes de descontinuidade, apesar do clima otimista que se gerou em torno deste governo. Por esta forma de condução da política de saúde verificou-se que a tensão entre o paradigma da Reforma Sanitária e o privatista persistiu por todo governo Lula e vem se reproduzindo no governo de Dilma Rousseff. A partir de 2005, aproximadamente, a relação público e privado na saúde está continuamente sendo refuncionalizada, adquirindo conteúdo distinto no âmbito do novo desenvolvimentismo com ênfase na gestão e de custo-benefício dos serviços.

Nos últimos anos os compromissos democrático-populares em relação aos direitos sociais e as ações do governo se revelaram tensionadas concomitantemente, por três perspectivas: a) proposta liberal do Estado mínimo, o paradigma privatista; b) defesa dos direitos reconhecidos pelos intelectuais tradicionais de peso na academia e no PT, mas implementados de forma flexibilizada, com parcerias e inovações na gestão; e c) defesa da universalização da saúde como direito fundamentado nos princípios da Reforma Sanitária.

Como pretendemos conhecer as teses do novo desenvolvimentismo e sua influência no SUS, continuaremos no item final deste texto a problematizar mais a conjuntura dos anos 2000 na saúde. Por ora, tratamos de recuperar alguns fundamentos do novo desenvolvimentismo. Não é fácil delimitar o período exato em que as ideias do novo desenvolvimento começam se manifestar. A fronteira entre a proposta de cunho liberal e a progressista-flexibilizada parece não ser mais tão clara, com a incorporação das ideias do novo desenvolvimentismo. É na adoção do ideário do novo desenvolvimento que as duas perspectivas parecem se confundirem e se tornarem parceiras ${ }^{2}$.

\section{As bases do novo desenvolvimentismo e a particularidade da perspectiva brasileira}

No início dos anos 2000 surgem críticas dentro do próprio sistema à lógica da política neoliberal, pois suas ações de liberalização comercial, desregulamentação financeira, restrição de direitos trabalhistas e privatizações das estatais, não possibilitaram crescimento econômico e desenvolvimento social. Do mesmo modo, não resolveram os problemas fiscais do Estado, pois os níveis de acumulação do capital aumentavam numa situação de instabilidade, os indicadores da desigualdade social estavam em expansão, os mecanismos da política econômica promoveram uma brutal transferência monetária para os setores rentistas e impediram o aumento do emprego. Prevaleciam políticas econômicas preocupadas apenas com controle da inflação e do orçamento (MATTEI, 2011).

Os governos que representam os setores progressistas na América Latina, no início do novo século, chegaram ao comando com posições anti-imperialistas, em defesa do desenvolvimento nacional autossustentável, fazendo críticas às políticas neoliberais, destacando seus resultados nefastos em termos de autonomia e desenvolvimento dos Estados nacionais (MOTA; AMARAL; PERUZZO, 2010). Neste sentido, o governo Lula é a expressão mais contundente da realidade brasileira e com reconhecimento internacional. Para chegar ao poder, Lula e o PT fizeram aliança com o capital produtivo como se fosse uma estratégia de oposição ao capital especulativo. Desta aliança começou a emergir um novo projeto de desenvolvimento para o país que pretendia se contrapor ao período anterior. Contudo, as raízes inspiradoras do novo desenvolvimento, que não são exclusivamente nacionais, e seus fundamentos não se relacionam com o período do nacional-desenvolvimentismo, pois encontra suas bases numa transição progressiva e pactuada do que ficou conhecido, segundo Gonçalves (2012), como Consenso de Washington Ampliado.

Nasce deste quadro uma perspectiva revisionista, que passa ser reconhecida como novo desenvolvimentismo. Esta proposta, incorporada pela Comissão Econômica para América Latina (Cepal) e com determinações do Banco Mundial, se organiza com vistas a minorar os impactos sociais e econômicos nos países da periferia do capitalismo causados pelas políticas dos anos 1990 (MATTEI, 2011). Dessa forma, o novo desenvolvimentismo propõe um novo padrão de intervenção do Estado na economia em consonância com a área social. De acordo com Mattei (2011) formou-se um consenso desenvolvimentista para resolver os 
problemas de ordem econômica e social nos continentes Asiático, Africano e Latino-Americano, que recebeu apoio da ONU e de seus diversos órgãos internos.

O debate do desenvolvimentismo foi reposicionado pela Cepal, segundo Mota, Amaral e Peruzzo (2010) em face das reformas do mercado e da crescente financeirização do capital. As discussões sobre o desenvolvimento econômico e social passam a ser orientadas pelas reformas estruturais na economia, com destaque para a política de privatização dos serviços públicos, reforma do Estado e focalização de programas sociais.

A perspectiva do desenvolvimento econômico e social adotada pelo Banco Mundial conta, dentre os seus formuladores, o economista indiano Amartya Sen, sendo veiculada na obra Desenvolvimento como Liberdade. Para Sen (2000), o desenvolvimento não pode ser medido apenas pelo crescimento do PIB e promoção da industrialização, mas é necessário considerar a expansão das capacidades para as pessoas levarem o tipo de vida que valorizam. A expansão das capacidades tem o sentido de liberdade e esta, por sua vez, é determinante da iniciativa individual, da eficácia social e permite ao indivíduo ser um agente da sua vida pessoal, do mercado e da esfera pública.

Entre os estudiosos brasileiros que tratam dos fundamentos do novo desenvolvimento, Mattei (2011) mapeou sua gênese identificando três escolas de pensamento econômico envolvidas, destacando a liderança da Fundação Getúlio Vargas, do Instituto de Economia da Universidade Federal do Rio de Janeiro e a do Instituto de Pesquisas Econômicas Aplicadas, IPEA. A fronteira entre elas nem sempre é muito clara, por vezes se sobrepõem, mas possuem em comum uma agenda de debates e um conjunto de proposições que visam apresentar uma estratégia alternativa, tanto à ortodoxia convencional como ao antigo nacional desenvolvimentismo.

Apresentaremos a visão do grupo de novos desenvolvimentistas ligado ao IPEA, sob a liderança do professor Marcio Pochmann, por entender que foi a perspectiva que deu suporte às ações do governo Lula e da presidente Dilma. Estes estudiosos, além de tratarem de ações mais abrangentes do Estado como a recuperação do crescimento econômico, combatem a degradação das condições de vida, enfatizam a necessidade da sustentabilidade dos sistemas ambientais, defendem que o Estado seja ator decisivo na definição e condução de estratégias de desenvolvimento. Para o desenvolvimento brasileiro, o grupo propõe sete eixos: a) Inserção internacional soberana; b) Macroeconomia para o pleno emprego; c) Infraestrutura econômica, social e urbana; d) Estrutura tecnoprodutiva avançada e regionalmente articulada; e) Sustentabilidade ambiental; f) Proteção social, direitos e oportunidades; g) Fortalecimento do Estado, das instituições e da democracia.

O projeto desenvolvimentista destes pesquisadores, segundo Mattei (2011), em termos de perspectiva política resgata o sentimento nacionalista e propõem que o Estado deva ser forte para levar o país igualmente ao desenvolvimento econômico e social.

Em termos de política social, esta vertente tem um caráter nacionalista e indica ações mais estruturantes do Estado em relação às necessidades sociais, mas sequer reafirma os direitos sociais da Carta de 1988. Aponta para um sistema tributário que não penalize os mais pobres, mas igualmente defende programas focalizados e oportunidades no mercado para os segmentos vulneráveis. Neste modelo de desenvolvimento, o acesso aos direitos sociais e econômicos se transformou em acesso a serviços, a poder de compra e a crédito.

\section{A Saúde e o desenvolvimento}

As implicações das ideias de desenvolvimento no âmbito da saúde podem ser identificadas claramente a partir de ações do Ministério da Saúde desde 2003. Destacam-se a seguir algumas ações que tem uma perspectiva revisionista dos princípios do SUS que, no geral, enfatizam os fundamentos do novo desenvolvimento e as inovações da gestão pública por meio do direito privado:

a) a Política Nacional de Humanização (PNH), criada em 2003, tem como diretriz atuar no cotidiano incentivando trocas solidárias entre gestores, trabalhadores e usuários. Os conceitos que norteiam o trabalho da PNH - como o acolhimento, gestão participativa e cogestão, ambiência, clínica ampliada e compartilhada, valorização do trabalhador e defesa dos direitos dos usuários (BRASIL, 2004) - ocultam as contradições, os interesses de mercado que perpassam o sistema, não fazendo referências à base material do SUS, limitandose essencialmente ao nível das relações entre trabalhador e usuário nos serviços;

b) o Pacto pela Saúde, lançado em 2006, em termos de gestão representou um avanço em relação às Normas Operacionais Básicas (NOBs) e às Normas Operacionais de Atenção a Saúde (NOAS) do SUS. É significativa a reafirmação do SUS no Pacto, pois as NOBs e as NOAS, ao tratarem das formas de operacionalizar a gestão, ignoravam seus fundamentos. Ao mesmo tempo, o documento expressa o conjunto de interesses em jogo na área da saúde e a sua implementação, ao invés de reafirmar as bases do SUS, parece estar se reduzindo a pactuação de indicadores no qual os gestores devem mostrar produção e concorrerem pela produtividade; 
c) a proposta de criação das Fundações Estatais de direito privado, embora não sendo aprovada ${ }^{3}$ na $13^{\mathrm{a}}$ Conferência Nacional de Saúde em 2007, foi enviada ao Congresso Nacional como Projeto de Lei Completar 92/2007, de criação das Fundações. O grande debate, que se instalou em várias instâncias acadêmicas, sindicais e parlamentares, fez com que em meados de 2009 o governo retirasse este projeto de tramitação no Congresso, mas não impediu que nas esferas subnacionais as Fundações continuassem se estruturando. Em 2013 este Projeto de Lei voltou a tramitar nas Comissões do Congresso Nacional;

d) o Conselho Nacional de Saúde voltou a ter o ministro como seu presidente, que desde 2006 vinha sendo eleito por pessoas que não representavam o governo. Os ministros anteriores, Humberto Costa e José Gomes Temporão, por esta condição de não serem mais os presidentes, acabaram esvaziando a participação do executivo neste espaço. No governo Dilma Roussef, em 2011, para garantir a presença do ministro nas reuniões do Conselho e em clima de muitos tensionamentos, o Conselho elegeu o ministro Alexandre Padilha como seu presidente. Em dezembro de 2012 o CNS elegeu uma representante dos usuários para presidente (representante da Confederação Nacional dos Trabalhadores na Agricultura, Contag), mas a condução da gestão está revelando alinhamento, sendo pouco combativa com as políticas de flexibilização do SUS;

e) o Decreto n. 7.508/2011, que regulamenta a Lei n. 8.080/1990, dispõe sobre a organização, o planejamento, a assistência e a articulação inter-federativa do SUS. O seu texto é bastante operacional para os gestores e o papel deliberativo dos Conselhos de Saúde é substituído pelos termos ouvidos dos Conselhos nos processos de planejamento e no monitoramento dos Contratos Organizativos da Ação Pública de Saúde, COAP. O Decreto faz referência ao acesso, que deve ser universal, igualitário e ordenado, e que o COAP deve ser firmado entre os entes federativos, mas não deixa claro se o serviço do SUS deve ser prestado por gestor público e se o trabalhador da saúde deve contratado pelo regime público, abrindo as portas para as chamadas inovações na gestão pelo direito privado;

f) dias depois da $14^{\text {a }}$ Conferência Nacional de Saúde, em dezembro de 2011, ter rejeitado o Projeto de Lei da Empresa Brasileira de Serviços Hospitalares (Ebserh), a presidente sancionou a Lei n. 12.550/2011 criando-a. É uma empresa pública, com personalidade jurídica de direito privado, patrimônio público e vinculada ao Ministério da Educação, adotada como medida para resolver os problemas de gestão e de recursos humanos dos Hospitais Federais de Ensino. A Ebserh, com sede em Brasília, terá como subsidiária cada um dos Hospitais Universitários (HU) que a ela aderirem. A Empresa sendo gerida pelo direito privado poderá priorizar o atendimento aos usuários do SUS que tenham planos privados, pois este resultará na dupla obtenção de recursos. Na prática, a gerência da Empresa terá poderes para firmar contratos, convênios, contratar pessoal técnico, definir processos administrativos e definir metas de gestão, restringindo sumariamente a vinculação dos HUs às Universidades e com os princípios do SUS;

g) o governo Lula passou todos os anos sem enfrentar o problema do financiamento da saúde. Em janeiro de 2012 a presidente Dilma sancionou a nova versão da Emenda Constitucional n. 29, pela Lei Complementar n. 141/2012, e a saúde universal no Brasil obteve mais uma grande derrota no financiamento de suas ações e serviços. A proposta que estipulava investimento de $10 \%$ das receitas correntes brutas da União para a área foi derrubada, mesmo tendo sido reafirmada pela $14^{\mathrm{a}}$ Conferência Nacional de Saúde em dezembro de 2011. Segundo o artigo $5^{\circ}$, a União aplicará, anualmente, em ações e serviços públicos de saúde, o montante correspondente ao valor empenhado no exercício financeiro anterior, acrescido de, no mínimo, o percentual correspondente à variação nominal do Produto Interno Bruto (PIB) ocorrida no ano anterior. Devendo os estados aplicarem $12 \%$ da sua receita e os municípios $15 \%$, conforme a versão de 2000;

Estas são algumas das grandes ações em relação ao SUS que se caracterizam pelo caráter revisionista e flexibilizado dos seus fundamentos e que se somam com a perspectiva de conciliar desenvolvimento econômico com desenvolvimento social, ignorando o reconhecimento constitucional da saúde como direito universal, a natureza do serviço público estatal regido pelas normas do direito público e as aprovações das plenárias de participação popular. Não se reivindica aqui o direito a saúde de acesso universal sem qualquer critério em forma de protocolos e fluxos, mas o respeito aos princípios organizacionais do sistema como a descentralização, a municipalização, a regionalização e a elaboração de Planos de Saúde Quadrienais com metas para o período.

\section{Considerações finais}

Apesar de todos estes indicadores de flexibilização e de revisionismo, afirmamos que o SUS é a maior política social brasileira nos últimos vinte cinco anos. E por ser uma política social universal, tem: ampla dimensão em termos da rede de serviço público e convênios com o setor filantrópico e privado, que vai da atenção primária à média e alta complexidade; grande estrutura de gestão nas três esferas de governos; um financiamento vinculado que só é menor em relação ao da educação; envolve uma série de indústrias para produzir 
seus suprimentos que vão desde o algodão, aos medicamentos e equipamentos médico-hospitalares; milhares de trabalhadores de diferentes áreas; uma grande rede de escolas e universidades públicas e privadas para formar os profissionais e realizar pesquisas; inúmeros institutos e laboratórios públicos de pesquisas e produção de medicamentos, vacinas e insumos. É por esta dimensão que o SUS é uma política social extremamente visada, disputada e tensionada por vários segmentos e interesses socioeconômicos e políticos.

Estes anos do SUS estão marcados pelas disputas entre os projetos políticos, ideológicos e econômicos que orientam sua implantação. Até meados dos anos 2000 se identificava que o SUS estava marcado pela disputada entre o projeto da Reforma Sanitária e o projeto privatista, mas recentemente vimos tomar corpo a perspectiva revisionista que parece, de alguma forma, fazer a conciliação entre os dois projetos. Esta terceira perspectiva nasceu de vários argumentos: o ideário crítico não dá conta de analisar a estrutura/conjuntura contemporânea; as várias entidades e sujeitos políticos que construíram e defenderam o SUS e suas bandeiras envelheceram; os interesses pessoais e corporativos nas mesas de negociações e nos cargos do Ministério da Saúde, juntamente com as pressões financeiro-eleitorais por parte do setor privado da saúde e das elites nacionais, os acordos com bancos Internacionais e a própria Organização Mundial da Saúde agiram para que o sistema público se limite a atenção primária.

É com base no conjunto de determinações apresentadas ao longo do texto que sustentamos nossa afirmação que o SUS perdeu sua radicalidade democrática, não por que seus princípios deixaram de existir, mas devido às interpretações e leituras que se tem feito deles, fazendo com que a saúde passe a ser sinônimo de desenvolvimento na medida em que se reconheça toda a sua dimensão e o potencial de expansão e lucratividade para o mercado. $\mathrm{O}$ reconhecimento desta sua dimensão mercadológica permitiu colocar o setor saúde como mais um pilar no processo de desenvolvimento do país. Desenvolvimento que parece estar sendo medido, não pela dimensão da saúde como direito universal da sua população e pelo avanço civilizacional para sociedade brasileira, mas pelo seu potencial mercadológico. O projeto do novo desenvolvimento representa, pela via do mercado, um conjunto de ações de governos, empresários e trabalhadores visando defender seus próprios interesses diante de um cenário global imperialista em busca de maiores taxas de lucros.

Em síntese, a saúde, como um direito coletivo, vem se transformando em saúde e desenvolvimento. Para este desenvolvimento o mercado é um sujeito importante. A integralidade vem sendo substituída por humanização, qualidade, acolhimento e vínculo. O importante é o acesso (seja por qualquer meio), não mais como obrigação do Estado e estratégia de superação da desigualdade social, que é estruturante da realidade brasileira. A participação deliberativa e propositiva (protagonismo popular) vem sendo ignorada e substituída por colegiados consultivos e de monitoramento, e por uma série de inovações institucionais na gestão.

\section{Referências}

ANTUNES, R. A desertificação neoliberal no Brasil. Campinas, SP: Autores Associados, 2004.

BARROS, E. Implementação do SUS: recentralizar será o caminho? Revista Ciência \& saúde coletiva. Rio de Janeiro: Abrasco, v. 6, n. 2, p. 307-310, 2001.

BORÓN, A. A trama do neoliberalismo. In: SADER. E.; GENTILLE, P. (Org.). Pós-neoliberalismo. Rio de Janeiro: Paz e Terra, 1995. BRASIL. Ministério da Saúde. Lei n. 8.080, de 19 de setembro de 1990. Dispõe sobre as condições para a promoção, proteção e recuperação da saúde, a organização e o funcionamento dos serviços correspondentes e dá outras providências. Disponível em: <http:/ /conselho.saude.gov.br/legislacao/lei8080_190990.htm>. Acesso em: 12 jan. 2014.

Lei n. 8.142, de 28 de dezembro de 1990. Dispõe sobre a participação da comunidade na gestão do Sistema Único de Saúde (SUS) e sobre as transferências intergovernamentais de recursos financeiros na área da saúde e dá outras providências. Disponível em: <http://www.planalto.gov.br/ccivil_03/leis/18142.htm>. Acesso em: 12 jan. 2014.

Lei n. 9.637, de 15 de maio de 1998. Dispõe sobre a qualificação de entidades como organizações sociais, a criação do Programa Nacional de Publicização, a extinção dos órgãos e entidades que menciona e a absorção de suas atividades por organizações sociais, e dá outras providências. Brasília, 15 maio de 1998.

Medida Provisória n. 2.177-44, de 24 de agosto de 2001. Altera a Lei n. 9.656, de 3 de junho de 1998, que dispõe sobre os planos privados de assistência à saúde e dá outras providências.

.Humaniza SUS: política nacional de humanização: documento base para gestores e trabalhadores do SUS/Ministério da Saúde, Secretaria-Executiva, Núcleo Técnico da Política Nacional de Humanização. Brasília: Ministério da Saúde, 2004.

Mais saúde: direito de todos: 2008-2011. Brasília: Ministério da Saúde, 2007.

. Lei complementar n. 141, de 13 de janeiro de 2012. Regulamenta o $§ 3^{\circ}$ do art. 198 da Constituição Federal para dispor sobre os valores mínimos a serem aplicados anualmente pela União, Estados, Distrito Federal e Municípios em ações e serviços públicos de saúde... Brasília, 2012.

Relatório da $14^{a}$ Conferência Nacional de Saúde: todos usam o SUS: SUS na seguridade social: política pública, patrimônio do povo brasileiro. Brasília: Ministério da Saúde, 2012. 
Caderno de diretrizes, objetivos, metas e indicadores: 2013-2015. Brasília: Ministério da Saúde, 2013.

BRAVO, M. I. A política de saúde no Brasil. In: MOTA, A. E. et al. (Org.). Serviço Social e saúde. São Paulo: Cortez, 2007, p. 88-110. BRAVO, M. I.; MENEZES, J. A política de saúde no governo Lula: algumas reflexões. In: BRAVO, M. I.; D'ACRI, V.; MARTINS, J. B. (Org.). Movimentos sociais, saúde e trabalho. Rio de Janeiro: ENSP/Fiocruz, 2010, p. 45-69.

COUTO, C. G.; ARANTES, R. B. Constituição ou políticas públicas? Uma avaliação dos anos FHC. In: ABRUCIO, F. L.; LOUREIRO, M. R. (Org.). O Estado numa era de reformas: os anos FHC - parte 1. Brasília: MP; Seges, 2002, p. 75-120.

BELLUZZO, L. G. Os anos do povo. In: SADER, E. (Org.). Lula e Dilma: 10 anos de governos pós-neoliberais no Brasil. Rio de Janeiro: Flacso, 2013.

FIORI, J. L. O Brasil e seu entorno estratégico na primeira década do século XXI. In: SADER, E. (Org.). Lula e Dilma: 10 anos de governos pós-neoliberais no Brasil. Rio de Janeiro: Flacso, 2013.

GONÇALVES, R. Novo desenvolvimentismo e liberalismo enraizado. Serviço Social \& Sociedade. São Paulo: Cortez, n. 112, out./dez. 2012, p. 637-670.

IDISA - Instituto de Direito Sanitário Aplicado. Temporão permanecerá irredutível na defesa das fundações estatais para hospitais. Campinas, SP, 19 novembro de 2007.

MATTEI, L. Gênese e agenda do novo desenvolvimentismo brasileiro. 2011. In: IV ENCONTRO INTERNACIONAL DAASSOCIAÇÃO KEYNESIANA BRASILEIRA (AKB). Anais... Rio de Janeiro, 2011. Disponível em: <http://www.ppge.ufrgs.br/akb/encontros/2011/ 10.pdf $>$. Acesso em: 12 jan. 2014.

MOTA, A. E.; AMARAL, A. S.; PERUZZO, J. F. O novo desenvolvimentismo e as políticas sociais na América Latina. In: MOTA, A. E. (Org.). As ideologias da contrarreforma e o Serviço Social. Recife: Ed. da UFPE, 2010, p. 35-67.

NOGUEIRA, V. M. R. O direito à saúde na reforma do estado brasileiro: construindo uma nova agenda. Tese (Doutorado em Enfermagem) - Programa de Pós-Graduação em Enfermagem, Universidade Federal de Santa Catarina. Florianópolis, 2002.

PEREIRA, L. C. Bresser. A reforma do Estado nos anos 90: lógica e mecanismos de controle. Brasília: Ministério da Administração e Reforma do Estado. Caderno 1. Brasília - DF / 1997.

SADER, E. A construção da hegemonia pós-neoliberal. In: SADER, E. (Org.). Lula e Dilma: 10 anos de governos pós-neoliberais no Brasil. Rio de Janeiro: Flacso, 2013.

SEN, A. Desenvolvimento como liberdade. Tradução de Laura Teixeira Motta. São Paulo: Cia. das Letras, 2000.

\section{Notas}

1 Texto Proposta de Emenda da Constituição n. 21, de 1995. Diário do Congresso Nacional (Seção 1), terça-feira, 28 de março de 1995, p. 44894496. Mensagem n 3 306/95: Modifica o sistema de Previdência Social, especialmente o Art. 196: "A saúde é direito de todos e dever do Estado, garantido, nos termos da lei, mediante políticas sociais e econômicas que visem à redução do risco de doença de outros agravos e ao acesso universal e igualitário às ações e serviços para sua promoção, proteção e recuperação". Disponível em: 〈http://www.camara.gov.br/proposicoesWeb/ fichadetramitacao?idProposicao=169281>. Acesso em: 14 jan. 2014.

2 Cabe deixar claro que não existe unanimidade sobre a perspectiva do novo desenvolvimentismo como característica do governo Lula e da presidente Dilma. Ver os textos que caracterizam estes dois governos como pós-neoliberal na obra de Sader (2013) e Gonçalves (2012).

3 "O Ministério da Saúde continuará irredutível na busca de soluções para a gestão do Sistema Único de Saúde", afirmou José Gomes Temporão,

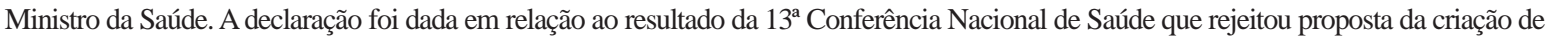
fundações estatais para a administração de hospitais públicos. [...] O governo federal se propõe a negociar alternativas dentro do projeto de lei já existente e encaminhado, mas será irredutível na busca de soluções para problemas de gestão da rede pública de saúde. "O governo respeita a opinião expressa na Conferência, mas continuará buscando, no Congresso Nacional, uma lei que permita ao SUS operar os seus hospitais com alguma eficiência", disse Temporão. (IDISA, 2007).

\section{Tânia Regina Krüger}

taniareginakruger@gmail.com

Doutora em Serviço Social pela Universidade Federal de Pernambuco (UFPE)

Docente do Departamento de Serviço Social da Universidade Federal de Santa Catarina (UFSC)

\section{UFSC - DSS}

Campus Universitário Reitor João David Ferreira Lima

Trindade

Florianópolis - Santa Catarina - Brasil

CEP: 88040-970 